\title{
BASE NACIONAL COMUM CURRICULAR: CIÊNCIAS E MULTICULTURALISMO
}

\author{
Lucas Munhoz CABRAL ${ }^{\mathrm{i}}$ \\ Rosana dos Santos JORDÃO ${ }^{\text {ii }}$
}

\begin{abstract}
RESUMO
A Base Nacional Comum Curricular - BNCC é o documento que concretiza a atual política curricular no Brasil, por meio da seleção de um conjunto de aprendizagens essenciais à formação básica. Dada a sua relevância educacional, analisamos a versão final desse documento, publicada em 2018, com o objetivo de verificarmos se elementos do multiculturalismo estão contemplados em seu texto geral e na parte específica da área de Ciências da Natureza. Para tanto, foram selecionados excertos que fazem menção a fundamentos éticos e a tratamentos direcionados à pluralidade, e foi feita a análise das habilidades designadas para a área das Ciências da Natureza do Ensino Fundamental I e II. Como resultado, identificamos que, embora a BNCC utilize argumentos pautados na defesa da igualdade de direitos às diversidades, apenas $1 \%$ das habilidades para as Ciências utilizam verbos associados à aprendizagem de valores. Além disso, a presença de habilidades potencialmente associadas ao multiculturalismo foi considerada reduzida e, em certos casos, superficial. Essa participação tímida do multiculturalismo na Base é um resultado preocupante, revelando o quão distante estamos de abordarmos o pluralismo além de um mero acordo moral.
\end{abstract}

PALAVRAS-CHAVE: Base Nacional Comum Curricular; Multiculturalismo; Currículo; Ensino de Ciências da Natureza; Políticas educativas.

\section{NATIONAL COMMON CURRICULAR BASE: SCIENCE AND MULTICULTURALISM}

\begin{abstract}
The National Common Curricular Base - known by the acronym BNCC - is the document that depicts the present Brazilian curricular policy through a selection of a set of apprenticeship for all the Basic Education. Given its educational importance, we analyzed the final version of this document, published in 2018, with the purpose of verifying if elements of multiculturalism are included in its general text and in the specific part of the area of Natural Sciences. To this end, excerpts that mention ethical foundations and treatments aimed at plurality were selected, and the analysis of the skills assigned to the area of Natural Sciences in Elementary School I and II was carried out. As a result, we identified that, although the BNCC uses arguments based on the defense of equal rights to diversities, only $1 \%$ of the skills for Science use verbs associated with the learning of values. In addition, the presence of skills potentially associated with multiculturalism was considered reduced and, in some
\end{abstract}

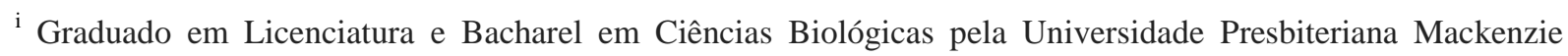
(2018). Professor de Ensino Médio e Técnico do Centro Paula Souza. E-mail: lucasmunhoz2796@gmail.com. ORCID: https://orcid.org/0000-0002-1148-2696

ii Doutorado em Educação pela Universidade de São Paulo (2005). Professor Adjunto da Universidade Presbiteriana Mackenzie. E-mail: rosana.jordao@gmail.com. ORCID: https://orcid.org/0000-0002-2180-031X
} 
cases, superficial. This timid participation of multiculturalism in the Base is a worrying result, revealing how far we are from approaching pluralism beyond a mere moral agreement.

KEYWORDS: National Common Curricular Base; Multiculturalism; Curriculum; Natural Science teaching; Educational policies.

\section{BASE NACIONAL COMÚN CURRICULAR: CIENCIA Y MULTICULTURALISMO}

\section{RESUMEN}

La Base Nacional Común Curricular es el documento que concreta la actual política curricular en Brasil, por medio de la selección de un conjunto de aprendizajes esenciales a la educación básica. Dada su relevancia educativa, analizamos la versión final de dicho documento, publicada en 2018, con el objetivo de verificar si elementos del multiculturalismo están contemplados en su texto general y en la parte específica del área de Ciencias de la Naturaleza. Para tanto, fueron seleccionados recortes que hacen mención a fundamentos éticos y a tratamientos dirigidos a la pluralidad y se hizo el análisis de las habilidades asignadas al área de las Ciencias de la Naturaleza. Como resultado, identificamos que, aunque la BNCC utilice argumentos pautados en la defensa de la igualdad de derechos a las diversidades, sólo el $1 \%$ de las habilidades de Ciencias utilizan verbos asociados al aprendizaje de valores. Además, la presencia de habilidades potencialmente asociadas al multiculturalismo, fue considerada reducida y, en algunos casos, superficial. Esta presencia tímida del multiculturalismo en la Base es un resultado preocupante, revelando lo lejos que estamos de abordar el pluralismo, más allá del mero acuerdo moral.

PALABRAS CLAVE: Base Nacional Común Curricular; Multiculturalismo; Currículum; Enseñanza de Ciencias de la naturaleza; Políticas educativas.

\section{INTRODUÇÃO}

A prática educativa pode levar a múltiplas possibilidades de formação de conhecimentos no espaço escolar. Para que essas diversas aprendizagens correspondam a um propósito educativo, devem ser referenciadas e selecionadas com base em um conjunto de objetivos pedagógicos (SANTOMÉ, 2013). Entretanto, a seleção do que se almeja ser aprendido nas escolas não é feita exclusivamente por elas. Como instituições sociais, existentes em um determinado contexto histórico, as escolas sofrem influência de uma série de instâncias externas que impactam sua ação educativa, tais como as secretarias de ensino e o Ministério da Educação (MEC), as universidades, as famílias, as editoras, dentre outras (LIBÂNEO, 2012).

A Base Nacional Comum Curricular (BNCC) representa um desses elementos externos à escola que, por meio da oficialização de um conjunto de aprendizagens essenciais à 
escolarização básica, pode influenciar as metas educativas nesses espaços. Tal documento deve servir de referência para a elaboração dos currículos de qualquer instituição escolar, desde a Educação Infantil até o final do Ensino Médio (BRASIL, 2018). Nesse aspecto, ressaltamos a importância da análise da BNCC, já que ela indica o sentido que o país quer dar à formação das futuras gerações. Contudo, em função da variedade de informações existentes nesse documento, deve existir um foco de análise, o qual, neste caso, diz respeito à pluralidade de culturas e de identidades, com especial atenção à área de Ciências da Natureza.

A preocupação com a pluralidade de culturas e de identidades relaciona-se à enorme diversidade própria do mundo contemporâneo e ao fato de a escola ser um espaço de encontro e de possíveis conflitos relacionados às diferenças. Dessa maneira, justificam-se investigações críticas sobre a forma como essa diversidade é apresentada e abordada pela BNCC, tendo em vista que os objetivos de aprendizagem propostos nesse documento influem no tratamento dado à pluralidade pelo ensino. Tais objetivos, de modo intencional ou não, alinham-se a um conjunto de valores, conhecimentos e abordagens relativos à diversidade e às relações culturais dela provenientes (SANTOMÉ, 1998; MOREIRA; CANDAU, 2007).

Assim, nosso objetivo é verificar se o documento contempla ou não elementos do multiculturalismo em seu texto geral e na parte específica da área de Ciências da Natureza. Em caso positivo, analisaremos a maneira como tais elementos são apresentados. Tomamos como objeto de análise a última versão da Base Nacional Comum Curricular para o Ensino Fundamental, publicada no início de 2018.

\section{CULTURA E MULTICULTURALISMO}

O contexto social é inegavelmente plural. Em qualquer espaço, convivemos com a diversidade, seja ela referente à cultura, à identidade ou a modos de vida, o que nos leva a possíveis conflitos ligados a tais diferenças (SANTOS; LOPES, 2008; MOREIRA, 2005; CANEN, 2015). O multiculturalismo insere-se nesse contexto como um movimento político e teórico que busca respostas às problemáticas relacionadas à pluralidade (FERREIRA, 2012).

No âmbito do ensino, refere-se a qualquer prática, abordagem ou propósito que busque reverter as lacunas que os espaços educativos apresentam em relação à diversidade de culturas, identidades ou a qualquer forma de diferença. Embora não seja um movimento 
homogêneo, o multiculturalismo insere-se no ensino como uma alternativa que se opõe a situações de exclusão, de silenciamento e de marginalização de culturas e de identidades nas escolas, além de ser base teórica à proposição de novas metas formativas e curriculares que substituam o paradigma da hegemonia cultural (CANEN, 2000; SILVA, 1999).

Para abordarmos o multiculturalismo, é necessário que explicitemos nossa compreensão sobre cultura, diferença e identidade. A cultura pode ser entendida como uma dimensão da vida social, da qual fazem parte as práticas cotidianas, isto é, as produções e os modos de agir, de viver e de pensar de um grupo específico. Ela compõe um sistema de significados pelo qual as populações desenvolvem e comunicam seus conhecimentos e atividades próprias, sendo continuamente construída (FERREIRA, 2012). Em outras palavras, podemos afirmar que a cultura é o produto coletivo da história de cada sociedade (SANTOS, 2017).

Partindo do pressuposto de que a história dos agrupamentos humanos é diferenciada a cada realidade local, econômica e geográfica, entende-se que as culturas sejam também diversas. Essas culturas, por sua vez, são uma das fontes primárias para o processo de formação de consciências, influenciando, portanto, nas relações que os sujeitos, também biologicamente diversos, estabelecem com a realidade em que vivem. Assim sendo, a definição de cultura na concepção multicultural não condiz com a perspectiva de que existe apenas uma forma de se entender o mundo, tipicamente associada aos que detém o poder (SODRÉ; TRINDADE, 2002).

Em relação às diferenças, entende-se que a diversidade faz parte do acontecer humano. Entretanto, essas diferenças só são "reconhecidas" a partir do momento que são denominadas e identificadas. Dessa maneira, a forma com que as concebemos caracteriza-se como um processo ligado às relações de poder (GOMES, 2007). Ferreira (2012), por sua vez, avalia que esse processo de diferenciação tem um papel importante na constituição das identidades, defendendo que o que somos também pode ser definido em relação àquilo que não somos. Por essa razão, a identidade forma-se dialogicamente, o que a caracteriza como uma construção mutável. Para Canen (2007), a identidade também é híbrida, isso porque os indivíduos se constituem por uma multiplicidade de marcas.

O próprio multiculturalismo também é fruto de interpretações variadas, resultando em um movimento heterogêneo e muitas vezes contraditório. Dado que esse termo é polissêmico, 
neste trabalho, vamos nos ater às categorias criadas por Canen (2015), que propõe distintos sentidos para o multiculturalismo. No primeiro, chamado de "reparador", o tratamento dado à pluralidade reduz-se a ações para garantir o acesso de grupos marginalizados a espaços educacionais. Não há, neste caso, preocupações com intervenções curriculares. O segundo tipo é denominado de "folclorismo", em que o multiculturalismo é visto como uma medida de valorização de costumes, festas, receitas ou outros aspectos "exóticos" das diferentes culturas. O terceiro refere-se ao "reducionismo identitário", que reconhece a diversidade e a necessidade do combate à construção das diferenças, mas vê a identidade como um marcador imutável; desse modo, as pessoas são interpretadas como essência acabada de algum grupo específico. O quarto, por sua vez, é visto como "guetização cultural". Essa categoria trata do reconhecimento de um único padrão cultural específico, impedindo o diálogo entre grupos distintos (CANEN, 2015).

Assim, como alternativa, Canen (2007) propõe o que chama de multiculturalismo crítico pós-moderno ou pós-colonial, buscando evitar a homogeneização ou estereotipia cultural, por meio do desafio às relações de poder e aos discursos responsáveis pela construção das diferenças e dos preconceitos. Também é papel dessa linha multicultural, de acordo com Silva e Moreira et al. (1999 apud FERREIRA, 2012), estimular o conhecimento sobre as razões dos conflitos entre seres humanos, a empatia, o combate a qualquer forma de discriminação, a valorização das realizações de indivíduos e grupos distintos e, por fim, a proposição de formas adequadas de vivência em uma sociedade plural.

\section{O ENSINO DE CIÊNCIAS E O MULTICULTURALISMO}

Não há atualmente uma forma única e consensual de compreender-se a Ciência. No senso comum, essa área é vista como uma epistemologia privilegiada, de outro modo, como a instituição que nos possibilitaria conhecermos pressupostas "verdades" sobre os fenômenos estudados (JAFELICE, 2017). Tal patamar elevado, no qual a Ciência foi historicamente posicionada, constrói um imaginário de instituição inquestionável, por supostamente ser alheia aos resultados daquilo que produz, sejam eles positivos ou negativos (MORIN, 2008). Essa visão pode servir a fins ideológicos, reforçando para a população valores das classes dominantes, por meio de discursos pretensamente neutros (LEWONTIN, 2001). 
Na contramão dessa compreensão, há outra que concebe a construção coletiva da Ciência como produto de um dado momento histórico, de uma determinada situação econômica e política e formada por interesses de diversas instituições. Em outras palavras, ela é construída e transformada no contexto social em que se insere, podendo ser considerada como parte integrante da cultura (JAFELICE, 2017; LEWONTIN, 2001).

Por filiarmo-nos a essa segunda compreensão e considerarmos a Ciência como constituinte do fazer social, julgamos ser necessário um ensino de Ciências voltado ao entendimento não só de saberes específicos dessa área, mas também de atitudes, de valores e de competências que levem à compreensão das implicações pessoais, sociais, econômicas e ambientais da Ciência (CACHAPUZ; PRAIA; JORGE, 2004). Dito de outra forma, o ensino de Ciências deve ter como foco a formação de pessoas capazes de reconhecer o espaço em que vivem e de decidir e intervir, por conta própria, em situações que envolvam conhecimentos científicos e tecnológicos (CACHAPUZ et al., 2005).

Para tanto, é importante, no âmbito do ensino, a substituição de um viés estritamente descritivo e factual, que se resume ao "enciclopedismo", por uma dimensão "sócio construtivista" (CACHAPUZ; PRAIA; JORGE, 2004). Para essa perspectiva, a formação científica deve partir dos diversos contextos culturais e saberes prévios dos discentes, estimulando-os a construírem conhecimentos por meio da provocação, da investigação e do entendimento profundo dos conteúdos.

É no contexto dessa compreensão da Ciência e de seu ensino que a concepção multicultural pode ser inserida, cumprindo a função de ser o elo que potencialmente rompe com o distanciamento consolidado entre a visão científica e os fatores sociais, políticos, culturais e econômicos que fazem parte do viver humano. Na proposta apresentada, portanto, a cultura e suas interrelações participam do aprendizado sobre as Ciências, possibilitando até mesmo o rompimento da noção positivista dessa área, tida como única forma válida de conhecimento, já que contribui para o reconhecimento da diversidade de explicações do mundo, sem a desqualificação de nenhuma delas (BARBOSA, 2010). O multiculturalismo pode, ainda, favorecer a compreensão dos contextos históricos da Ciência frente às diversidades e às suas variadas formas de intervenção ou de engajamento na sociedade, de modo a formar sujeitos que vejam a diferença como um fator de prosperidade. 
O multiculturalismo também se faz necessário quando se abordam os saberes científicos diretamente relacionados à espécie humana, marcada por diferenças internas, regionalismos e variações de costumes e de etnias. Nesse sentido, é possível dizer que a presença do multicultural no ensino de Ciências também soma elementos à compreensão sobre o que é ser humano (KRASILCHICK, 2016).

Enfim, nosso objetivo não é desconsiderar as teorias e os saberes estritamente “científicos", pois acreditamos que são importantes. O que pontuamos anteriormente é a necessidade de compreendermos o valor das abordagens multiculturais para uma formação mais abrangente em Ciências, preocupada em desvelar o pressuposto distanciamento entre a Ciência, a sociedade e a cultura.

\section{O DESENVOLVIMENTO DA BNCC E SUAS CARACTERÍSTICAS}

A BNCC é o documento responsável por orientar conteúdos essenciais à Educação Básica, por meio da seleção de uma série de conhecimentos, competências e habilidades, que devem servir de referência nacional para a formulação de currículos em escolas dos Estados, do Distrito Federal e dos Municípios, assim como das propostas pedagógicas das instituições escolares privadas. Tal documento não deve ser implementado diretamente nos ambientes de ensino. Seu papel é subsidiar a elaboração do currículo desses espaços, literalmente funcionando como uma "base" (BRASIL, 2018).

A formulação da Base Nacional é uma exigência do Plano Nacional de Educação (PNE) e da Conferência Nacional de Educação (CONAE) (TRICHES; ARANDA, 2016). Além disso, recebe respaldo da Lei de Diretrizes e Bases da Educação Nacional (LDB) (BRASIL, 1996) e das Diretrizes Curriculares Nacionais da Educação Básica (DCN) (BRASIL, 2013), pautando-se em princípios éticos, políticos e estéticos, desenvolvidos nesses documentos (BRASIL, 2018).

Como se pode notar, a proposição de uma base não é uma preocupação nova. Segundo Cunha e Silva (2016), desde a década de 1980, já havia discursos que defendiam sua existência. A primeira versão da BNCC foi divulgada em 30 de julho de 2015, no Portal do MEC, para consulta pública. A partir de debates, críticas e sugestões, a equipe responsável por sua elaboração encarregou-se de reescrever as versões seguintes do documento. As 
entidades incumbidas pela sistematização dessas respostas foram o Conselho Nacional de Secretários de Educação (CONSED), a União Nacional de Dirigentes Municipais de Educação (UNDIME) e a União Nacional dos Conselhos Municipais da Educação (UNCME) (SOUSA, 2015).

Vale destacarmos a participação e o apoio oferecido pelo setor privado, representado por empresas dentre as quais: os bancos Itaú, Bradesco e Santander, a Natura, a Volkswagen e as fundações Roberto Marinho, Lemann, Ayrton Senna, além de outros grupos da sociedade civil, que produziram seminários e relatórios de análise do documento, como o Movimento pela Base Nacional Comum Curricular (MERCADO; FUMES, 2017; CARVALHO; SILVA; DELBONI, 2017).

Nos períodos de consulta pública, houve muitas discussões sobre a necessidade ou não da existência de uma base e sobre seus aspectos que precisariam de maiores mudanças. Enquanto muitos defendiam a proposta de uma diretriz comum, o principal argumento contra a BNCC estava assentado na ideia de que a padronização contempla os interesses dos grupos hegemônicos que têm representado a educação em nosso país, dando voz apenas a setores específicos da sociedade, o que evidencia esse contexto de disputas sobre perspectivas múltiplas (TRICHES; ARANDA, 2016; BATISTA; RIBEIRO, 2015).

Em termos de organização, a BNCC para o Ensino Fundamental, está dividida em anos iniciais ( $1^{\circ}$ ao $5^{\circ}$ anos) e anos finais ( $6^{\circ}$ ao $9^{\circ}$ anos). Os conteúdos estão agrupados em “Áreas do Conhecimento”, sendo elas Linguagens, Matemática, Ciências Humanas, Ciências da Natureza e, a partir da última versão, Ensino Religioso. Cada uma dessas áreas se subdivide em suas disciplinas específicas, denominadas componentes curriculares. Para cada componente, são apresentadas "competências específicas". As Ciências da Natureza constituem-se por um único componente curricular denominado "Ciências" (BRASIL, 2018).

Para organizar as aprendizagens essenciais a serem asseguradas nesse componente curricular, foram propostas três unidades temáticas que se repetem ao longo de todo o Ensino Fundamental: "Matéria e Energia", "Vida e Evolução" e "Terra e Universo". Cada unidade reúne um conjunto de habilidades que mobilizam conhecimentos conceituais, linguagens, processos e procedimentos de investigação envolvidos na dinâmica da construção de conhecimentos na Ciência (BRASIL, 2018). Associados a cada habilidade, são explicitados “objetos de conhecimento”. Destaca-se que, segundo a Base, “[...] os agrupamentos propostos 
não devem ser tomados como modelo obrigatório para o desenho dos currículos" (BRASIL, 2018, p. 325).

\section{ANÁLISE DO DOCUMENTO BNCC}

Nesta seção, partimos das estratégias para a análise das unidades da BNCC; em seguida, focamos no texto geral da BNCC; após, abordamos, mais especificamente a área de Ciências da Natureza; por fim, tratamos das habilidades a serem promovidas por essa área de ensino.

\subsection{Estratégias analíticas}

Conforme já apresentamos, nosso objetivo era verificar se a BNCC contempla ou não elementos do multiculturalismo em seu texto geral e na parte específica da área de Ciências da Natureza para o Ensino Fundamental I e II. Para tanto, adotamos a análise de conteúdo, tomando como referências Bardin (2006) e Franco (2005).

Selecionamos os seguintes tópicos: "Introdução" (BRASIL, 2018, p. 7); "A Etapa do Ensino Fundamental" (BRASIL, 2018, p. 57) e "A área de Ciências da Natureza” (BRASIL, 2018, p. 321). A partir desses tópicos, separamos a análise em três unidades:

- "texto geral";

- " "texto específico da área de Ciências da Natureza";

- "expectativas de aprendizagem em Ciências":

- verbos estruturantes das habilidades propostas no componente curricular de Ciências;

- habilidades potencialmente multiculturais.

Vale ressaltarmos que chamamos de texto, geral e específico, as partes da BNCC que se referem à explicação, à justificativa e à contextualização. As expectativas de aprendizagem em Ciências são os conceitos e as habilidades delimitados como foco de aprendizagem na Base.

Dessa forma, a primeira unidade, "texto geral", diz respeito à parte do documento que traz uma série de marcos legais, objetivos, pressupostos e contextos utilizados para explicar ou justificar a existência do documento em si. Já a segunda unidade, "texto específico à área 
de Ciências da Natureza", faz menção à importância da educação em Ciências, a sua finalidade pedagógica e aos fundamentos éticos dessa área (BRASIL, 2018).

Como estratégia para a análise dessas duas unidades, decidimos pela realização de recortes de trechos. Selecionamos excertos em que eram explicitados os fundamentos éticos do documento, bem como os que tratavam da pluralidade de culturas e de identidades. Em relação às "expectativas de aprendizagem em Ciências", enfocamos os verbos estruturantes que, de acordo com a BNCC, explicitam os processos cognitivos envolvidos no desenvolvimento de cada uma das habilidades e se referem às competências que se espera que os discentes desenvolvam (BRASIL, 2018). Tais verbos foram agrupados de acordo com o processo evidenciado por eles, a partir das seguintes categorias: verbos ligados à "aprendizagem de conceitos" de Ciências, classificar e nomear, por exemplo; verbos ligados à "aprendizagem de procedimentos", analisar e aplicar, por exemplo; e verbos ligados à “aprendizagem de valores", respeitar e valorizar, por exemplo.

Após a identificação e a ordenação dos verbos, partimos para a análise individual das habilidades consideradas potencialmente associadas ao multiculturalismo, com base no referencial adotado. Para que fosse possível discriminá-las do restante das habilidades apresentadas na Base, consideramos apenas aquelas em que era explícito algum procedimento, conceito ou atitude, voltados às identidades, aos modos de vida e de culturas, distinguindo-as das demais.

\subsection{Análise do texto geral da BNCC}

Conforme já mencionamos, chamamos de "texto geral" da BNCC os trechos introdutórios do documento, tanto a introdução geral (BRASIL, 2018, p. 7) como a parte em que se apresenta o Ensino Fundamental (BRASIL, 2018, p. 57). Nesses trechos, identificamos argumentos que poderiam ser considerados como associados ao multiculturalismo, muitas vezes utilizados nas justificativas para a existência da Base, pautados, em especial, em termos como "justiça", "democracia", "igualdade" e "equidade".

No seguinte excerto podemos encontrar um exemplo do uso de tais termos: "[...] a BNCC desempenha papel fundamental, pois explicita as aprendizagens essenciais [...] e expressa, portanto, a igualdade educacional sobre a qual as singularidades devem ser 
consideradas e atendidas" (BRASIL, 2018, p. 15, grifo do autor). Para a BNCC, portanto, o estabelecimento de aprendizagens essenciais, isto é, de um "patamar comum de aprendizagens a todos os estudantes" (BRASIL, 2018, p. 8), constitui-se em um meio para se almejar a igualdade na educação.

Ao propor os princípios sobre os quais a BNCC se assenta, o documento apresenta uma educação comprometida com “[...] princípios éticos, políticos e estéticos que visam à formação humana integral e à construção de uma sociedade justa, democrática e inclusiva [...]" (BRASIL, 2018, p. 7). Esses fundamentos indicam-nos que a BNCC aparentemente está alinhada ao pressuposto, defendido por Santomé (2013), de que a educação deve promover a formação de uma sociedade mais igualitária, no que concerne aos direitos e às oportunidades.

Nessa mesma direção, a BNCC alinha-se à Agenda 2030 para o desenvolvimento sustentável, da Organização das Nações Unidas (ONU), ao argumentar que a “[...] educação deve afirmar valores e estimular ações que contribuam para a transformação da sociedade, tornando-a mais humana, socialmente justa e, também, voltada para a preservação da natureza" (BRASIL, 2018, p. 8).

Como se pode observar, do ponto de vista das intenções, há o reconhecimento de que o Brasil é um país desigual e de que a educação deve ser um meio para transformar essa realidade, o que fica explícito no seguinte trecho:

O Brasil, ao longo de sua história, naturalizou desigualdades educacionais em relação ao acesso à escola, à permanência dos estudantes e ao seu aprendizado. São amplamente conhecidas as enormes desigualdades entre os grupos de estudantes definidos por raça, sexo e condição socioeconômica de suas famílias (BRASIL, 2018, p. 15).

Tomar a desigualdade existente no sistema educativo como ponto de partida impõe a defesa da necessidade de transformação desse contexto, sendo o currículo um dos instrumentos fundamentais para tanto (SANTOMÉ, 2012). A esse respeito, há coerência no discurso inicial da BNCC, na medida em que reconhece as desigualdades e se coloca como referência para a construção de currículos que possam enfrentá-las.

Entretanto, o currículo é uma seleção de um conjunto limitado de saberes culturais e que as decisões sobre essa seleção refletem relações de poder, quando configuram vozes presentes e vozes silenciadas em uma dada proposta educativa. Por essa razão, defender uma 
educação para todos é diferente de propor uma educação que represente a todos (CANEN, 2015).

Isso posto, é necessário analisarmos o tratamento que a BNCC dá às diversidades. No trecho a seguir, a Base sugere que

[...] os sistemas e redes de ensino e as instituições escolares devem se planejar com um claro foco na equidade, que pressupõe reconhecer que as necessidades dos estudantes são diferentes.

De forma particular, um planejamento com foco na equidade também exige um claro compromisso de reverter a situação de exclusão histórica que marginaliza grupos - como os povos indígenas originários e as populações das comunidades remanescentes de quilombos e demais afrodescendentes [...] (BRASIL, 2018, p. 15, grifo do autor).

Fica evidente, nesse trecho, que a BNCC associa o planejamento das instituições escolares ao reconhecimento das diferentes necessidades dos alunos, destacando grupos marginalizados como meta de inclusão educativa. Entretanto, em nosso ponto de vista, entendemos que, além do reconhecimento dessa diversidade, é essencial que tais diferenças sejam integrantes efetivas das metas nacionais de aprendizagem. Como proposto nas próprias Diretrizes Curriculares Nacionais, não podemos confundir os direitos civis, sociais e políticos com o direito à diferença. Enquanto o primeiro conjunto de direitos busca garantir o tratamento igualitário, o direito à diferença luta para que "[...] em nome da igualdade, não se desconsiderem as diferenças culturais, de cor/raça/etnia, gênero, idade, orientação sexual, entre outras" (BRASIL, 2017, p. 105).

Logo, é essencial que a escola represente de forma significativa essas diferenças, de tal modo que não se construam mecanismos de exclusão ou marginalização, que são uma afronta ao direito à educação, previsto a todos (BRASIL, 2017). É nesse sentido que Canen (2015) nos adverte para o fato de que um reconhecimento da diversidade voltado apenas à reparação de uma situação histórica não resulta necessariamente em uma proposta multicultural crítica.

Outro aspecto que merece análise é o sentido que a BNCC confere a termos fundantes do multiculturalismo, tais como: identidade, cultura e diversidade (CANEN, 2007; SANTOS; LOPES, 2008; FERREIRA, 2012). Em relação à identidade, ao apresentar o público a quem se destina o Ensino Fundamental, a BNCC afirma que devemos compreender o adolescente “[...] como sujeito em desenvolvimento, com singularidades e formações identitárias e 
culturais próprias, que demandam práticas escolares diferenciadas, capazes de contemplar suas necessidades e diferentes modos de inserção social” (BRASIL, 2018, p. 60).

Esse trecho mostra que a BNCC reconhece a existência da diversidade de identidades e a importância de escolhas pedagógicas específicas, destinadas a garantir uma formação a essa diversidade. Tal condição é, segundo Ferreira (2012), indispensável para se romper com desigualdades e discriminações. Essa compreensão também aparece em relação ao reconhecimento da diversidade cultural. "Atenta a culturas distintas, não uniformes e nem contínuas dos estudantes dessa etapa, é necessário que a escola dialogue com a diversidade de formação e vivências para enfrentar com sucesso os desafios de seus propósitos educativos" (BRASIL, 2018, p. 61-62, grifo nosso).

Nesse excerto, é possível notar o reconhecimento explícito da existência de diversas culturas dos discentes, como um conjunto não homogêneo. A noção de não continuidade dessas culturas nos remete ao argumento de Canen (2007), para quem a identidade de cada sujeito é formada por múltiplos marcadores constantemente construídos a partir de um processo dialógico-social. Em suma, ela defende que as identidades não são um fator acabado ou imutável, da mesma forma que a Base parece sugerir. É nesse mesmo aspecto, de reconhecimento e de valorização do diverso, que a BNCC também traz o argumento de que é preciso

[...] considerar a necessidade de desnaturalizar qualquer forma de violência nas sociedades contemporâneas, incluindo a violência simbólica de grupos sociais, que impõem normas, valores e conhecimentos tidos como universais e que não estabelecem diálogo entre as diferentes culturas presentes na comunidade e na escola. (BRASIL, 2018, p. 61, grifo nosso).

Quanto à essa afirmação, julgamos que "considerar a necessidade" da luta contra a violência é essencial, porém não suficiente. Os discursos responsáveis pela naturalização de formas discriminatórias precisam ser rompidos. É nesse sentido que o foco do multiculturalismo engajado criticamente se posiciona na transformação das relações sociais, culturais e institucionais, em que esses significados são gerados (MOREIRA, 2005). Por isso, seria importante que o texto da BNCC explicitasse um engajamento mais ativo nesse sentido.

Se é um objetivo da educação possibilitar a "[...] construção de uma sociedade justa, democrática e inclusiva" (BRASIL, 2018, p. 7), ela precisa se pautar em uma reconstrução reflexiva e contínua dos valores, modos e crenças da nossa sociedade (SANTOMÉ, 1998). 
Por fim, podemos afirmar que, no texto geral da BNCC, encontramos argumentos que indicam reconhecimento da pluralidade e atenção a uma formação significativa voltada à diversidade, mesmo que em alguns momentos essa preocupação com a diversidade tenha assumido contornos reparadores (CANEN, 2015).

\subsection{Análise do texto da área de Ciências da Natureza}

A análise do tópico "A área de Ciências da Natureza” da BNCC (BRASIL, 2018, p. 321) mostrou que há, no documento, uma preocupação com a aprendizagem de competências relacionadas à investigação. Há também trechos que aludem às diversidades, porém com menor ênfase do que no texto geral.

Mais especificamente, notamos que a Base assume o compromisso de desenvolver o letramento científico, que envolve "[...] a capacidade de compreender e interpretar o mundo (natural, social e tecnológico), mas também de transformá-lo com base nos aportes teóricos e processuais da ciência" (BRASIL, 2018, p. 321). Relacionada a essa perspectiva, a Base defende que "[...] apreender ciência não é a finalidade última do letramento, mas, sim, o desenvolvimento da capacidade de atuação no e sobre o mundo, importante ao desenvolvimento pleno da cidadania" (BRASIL, 2018, p. 321).

Tais trechos são coerentes com o que é defendido por Cachapuz, Praia e Jorge (2004), que enfatizam os impactos sociais, econômicos, éticos, políticos e culturais advindos da atividade científica. Por isso, esses autores defendem a relevância de um ensino de ciências voltado a uma aprendizagem multidimensional, que promova o reconhecimento desses impactos, bem como dos processos de produção de conhecimento, de modo a fomentar uma postura crítica frente aos produtos da Ciência e à sua relação com a sociedade. Os trechos destacados revelam-nos que, na BNCC (BRASIL, 2018), esse enfoque social e a capacidade procedimental passam a ser a finalidade principal do aprendizado de Ciências, dando a entender que são metas mais globais que a apreensão da Ciência por si só.

Outro objetivo posto para a área de Ciências da Natureza pela BNCC é garantir "[...] o acesso à diversidade de conhecimentos científicos produzidos ao longo da história, bem como a aproximação gradativa aos principais processos, práticas e procedimentos da investigação científica" (BRASIL, 2018, p. 321). Observa-se a preocupação com a compreensão da 
construção histórica da Ciência e da valorização dos procedimentos característicos do trabalho científico. Para alcançar tal meta, a BNCC enfoca a metodologia científica, defendendo que os estudantes devem aprender a definir problemas, levantar hipóteses, analisar possibilidades de resolução, comunicar resultados obtidos e propor ações de intervenção a partir deles. Essa perspectiva avança no sentido de superar a educação científica tradicionalmente reduzida à memorização de conhecimentos e fatos com fim em si mesmos (CACHAPUZ et al., 2005).

Ao colocar a investigação como foco da aprendizagem, a BNCC assume a perspectiva da alfabetização científica como um processo favorecido pela exploração, problematização, com provocações e situações de conflito, que levam à reconstrução de explicações prévias (CACHAPUZ; PRAIA; JORGE, 2004). No entanto, é preciso muito cuidado para que os alunos não entendam a Ciência de forma positivista. A ênfase no método científico pode reforçar a ideia de senso comum de que só há um método na Ciência e de que, por meio dele, é possível se chegar a explicações "verdadeiras" do mundo (BARBOSA, 2010).

Em relação às competências gerais da área de Ciências, a Base apresenta o seguinte posicionamento: "compreender as Ciências da Natureza como empreendimento humano, e o conhecimento científico como provisório, cultural e histórico" (BRASIL, 2018, p. 324). Ao assumir essa compreensão, a BNCC contraria a visão de senso comum sobre a Ciência, apresentada em Jafelice (2017), segundo a qual essa área é comumente interpretada com uma suposta superioridade epistemológica, reduzindo outras vertentes explicativas. Se tomarmos Morin (2008) como referencial, há na BNCC um alinhamento contrário a essa Ciência que se diz "inquestionável”, justamente por se posicionar alheia ao momento histórico, à sociedade, às culturas e até mesmo à subjetividade de quem a produz. Concordamos com esse posicionamento e com a ideia de que a Ciência não está acima das demais instituições sociais, como defende Lewontin (2001), sendo passível de críticas e de transformações.

Outra competência que merece destaque é a que evidencia o tratamento dado à diversidade:

Construir argumentos com base em dados, evidências e informações confiáveis e negociar e defender ideias e pontos de vista que promovam a consciência socioambiental e o respeito a si próprio e ao outro, acolhendo e valorizando a diversidade de indivíduos e de grupos sociais, sem preconceitos de qualquer natureza. (BRASIL, 2018, p. 324, grifo nosso). 
Embora esse tratamento apareça como um objetivo da área, é apresentado de modo genérico e bem mais reduzido do que no texto geral, que abordava aspectos referentes à desigualdade cultural e à discriminação, por exemplo. Em síntese, a BNCC, tanto em seu texto geral, como no relativo às Ciências da Natureza, mesmo que de formas distintas, explicita cuidados com a diversidade de culturas, muitas vezes utilizando-os como justificativa da sua existência no atual cenário educativo. Verificamos, também, coerência interna no documento, no que se refere aos fundamentos éticos e ao tratamento dado à pluralidade apresentados nos trechos estudados.

Dado esse resultado, nosso próximo passo foi averiguar se essa coerência constatada nesses trechos se manteria presente no texto de apresentação das habilidades essenciais a serem desenvolvidas por meio do ensino de Ciências da Natureza.

\subsection{Análise das habilidades a serem promovidas pela área das Ciências da Natureza}

As habilidades da BNCC são apresentadas por meio de verbos, complementos dos verbos e modificadores, que apresentam os conceitos atrelados ao processo cognitivo (BRASIL, 2018). Consideramos esses verbos muito importantes, pois se referem às expectativas de aprendizagem.

Por essa razão, inicialmente, identificamos e enumeramos cada um dos verbos presentes nas habilidades de Ciências para o Ensino Fundamental I e II. No total, contabilizamos 54 verbos diferentes, sendo estes utilizados 202 vezes, 89 para os anos iniciais e 113 para os finais. Em seguida, distribuímo-los nas categorias já mencionadas na metodologia, a lembrar: aprendizagem de conceitos, aprendizagem de procedimentos e aprendizagem de valores. Vale mencionarmos que alguns verbos foram utilizados tanto no ciclo dos anos iniciais quanto dos finais. Nessas situações, marcamos em negrito as repetições, conforme traz o Quadro 1.

Quadro 1 - Quantidade e frequência dos verbos usados nas habilidades de Ciências, para o Ensino Fundamental, de acordo com as categorias: associados à aprendizagem de conceitos, associados à aprendizagem de procedimentos e associados à aprendizagem de valores. 


\begin{tabular}{|c|c|c|c|c|c|}
\hline Categoria & Verbos (EF I) & $\mathbf{N}$ & Verbos (EF II) & $\mathbf{n}$ & $\begin{array}{c}\text { Número } \\
\text { total }\end{array}$ \\
\hline $\begin{array}{l}\text { Aprendizagem } \\
\text { de conceitos }\end{array}$ & $\begin{array}{c}\text { Descrever, identificar, } \\
\text { localizar, nomear, selecionar, } \\
\text { verificar. }\end{array}$ & 24 & $\begin{array}{c}\text { Calcular, caracterizar, } \\
\text { classificar, demonstrar, } \\
\text { descrever, diferenciar, } \\
\text { identificar, selecionar, } \\
\text { utilizar. }\end{array}$ & 30 & $\begin{array}{c}54 \\
(27 \%)\end{array}$ \\
\hline $\begin{array}{l}\text { Aprendizagem } \\
\text { de } \\
\text { procedimentos }\end{array}$ & $\begin{array}{l}\text { Analisar, aplicar, associar, } \\
\text { comparar, comunicar, } \\
\text { concluir, considerar, } \\
\text { construir, criar, destacar, } \\
\text { discutir, experimentar, } \\
\text { explicar, explorar, investigar, } \\
\text { justificar, manipular, } \\
\text { observar, organizar, produzir, } \\
\text { projetar, propor, reconhecer, } \\
\text { registrar, relacionar, relatar, } \\
\text { representar, testar. }\end{array}$ & 62 & $\begin{array}{l}\text { Analisar, argumentar, } \\
\text { associar, avaliar, comparar, } \\
\text { concluir, considerar, } \\
\text { construir, correlacionar, } \\
\text { deduzir, discutir, estabelecer, } \\
\text { executar, explicar, } \\
\text { implementar, inferir, } \\
\text { interpretar, investigar, } \\
\text { justificar, observar, planejar, } \\
\text { propor, reconhecer, } \\
\text { relacionar, representar, } \\
\text { simular. }\end{array}$ & 83 & $\begin{array}{c}145 \\
(72 \%)\end{array}$ \\
\hline $\begin{array}{c}\text { Aprendizagem } \\
\text { de valores }\end{array}$ & Acolher, respeitar, valorizar. & 3 & L & 0 & $\begin{array}{c}3 \\
(1 \%) \\
\end{array}$ \\
\hline Total & & 89 & & 113 & 202 \\
\hline
\end{tabular}

Fonte: Os autores conforme análise da BNCC.

O primeiro aspecto a ser ressaltado é a grande presença de verbos relacionados à aprendizagem de procedimentos de investigação, $72 \%(n=145)$, evidenciando uma coerência interna com aquilo que é apresentado no texto específico dessa área, ao menos no quesito do incentivo ao desenvolvimento do letramento científico. Em seguida, temos os verbos ligados à aprendizagem de conceitos, com presença de $27 \%(n=54)$. A diferença entre essas categorias pode indicar a superação da visão usualmente ligada ao aprendizado de Ciências, baseada mais na assimilação de fatos do que na reflexão sobre eles (JAFELICE, 2017). Merece destaque, também, a baixíssima presença de verbos ligados ao ensino de valores $(n=3), 1 \%$ do total. Esses resultados revelam uma tendência, a nosso ver problemática, de desqualificação dessas aprendizagens em comparação às demais.

Vale ressaltarmos também a presença apenas dos verbos "acolher, valorizar e respeitar" para designar as aprendizagens de atitudes em detrimento de outras possibilidades. Em relação às vertentes do multiculturalismo, esses verbos aproximam a BNCC das abordagens que defendem apenas o estímulo ao respeito, à tolerância e à convivência pacífica entre as pessoas. Embora tais verbos sejam importantes para o estabelecimento de relações sociais adequadas, julgamos que a perspectiva apresentada é limitada. Se considerarmos as interpretações mais críticas do multiculturalismo, como as de Canen (2015), seria desejável a 
presença de verbos que expressassem o reconhecimento das relações de poder e a necessidade do combate à sua naturalização, além da luta contra as discriminações e as desigualdades, tanto nas ações como nos discursos.

Nesse quesito, seria importante o acréscimo de alguns verbos como "engajar", ao tratar-se da luta contra discriminações; "criticar", ao abordarem-se temas atuais que tenham como pano de fundo visões apenas utilitaristas do ambiente, por exemplo. Seria interessante, também, relacionar tais verbos com o substantivo "empatia", que exprime a capacidade de colocar-se no local do outro.

Em síntese, consideramos que a BNCC apresenta uma distribuição bastante limitada de aprendizagens essenciais ligadas ao desenvolvimento de valores. Dado o papel social desse documento, como referência para a elaboração de currículos, tal dado é preocupante. Entendemos também que a justificativa apresentada no texto geral, que posicionava a Base frente à formação humana integral e que trazia a necessidade do estímulo de valores para a transformação social, não é efetivamente contemplada nas aprendizagens de Ciências propostas.

Passemos agora a um olhar mais minucioso em relação ao texto das habilidades que classificamos como relacionadas ao multiculturalismo. A princípio, cabe ressaltarmos que, de um total de 111 habilidades contabilizadas na Base, apenas seis delas correspondiam ao critério de serem "potencialmente associadas ao multicultural", proporcionalmente esse valor se refere a $5 \%$ do total averiguado. Desses resultados, duas habilidades são referentes ao Ensino Fundamental I e quatro ao Ensino Fundamental II.

(EF01CI05) Habilidade proposta ao $1^{\circ}$ ano de Ciências - objeto de conhecimento referente ao "respeito à diversidade".

"Comparar características físicas entre os colegas, reconhecendo a diversidade e a importância da valorização, do acolhimento e do respeito às diferenças" (BRASIL, 2018, p. 333).

Avaliamos que essa habilidade se refere a uma aprendizagem importante: o reconhecimento das diferenças físicas entre os sujeitos que fazem parte da sala de aula. Todavia, chamamos atenção para o cuidado que deve ser tomado na elaboração do currículo, a fim de que a questão da diversidade não fique limitada apenas a aspectos observáveis, quando a construção das diferenças extrapola os elementos biológicos, agregando fatores 
sociais, culturais e históricos (GOMES, 2007). Seria importante, neste caso, que as práticas pedagógicas a serem desenvolvidas no currículo não se limitem apenas à aparência física.

(EF04CI11) Habilidade proposta ao $4^{\circ}$ ano de Ciências - objeto de conhecimento referente aos "calendários, fenômenos cíclicos e cultura".

"Associar os movimentos cíclicos da Lua e da Terra a períodos de tempo regulares e ao uso desse conhecimento para a construção de calendários em diferentes culturas” (BRASIL, 2018, p. 339).

Nesse caso, temos uma habilidade que, se desenvolvida em uma perspectiva que problematize as diferenças e os aspectos culturais, pode vir a ser relevante. Contudo, considerando o quadro geral, preocupa-nos a possibilidade dessa proposta se concretizar em uma atuação isolada, que valorize apenas costumes ou aspectos "folclóricos", "exóticos" e pontuais, levando a uma concepção "folclorista" (CANEN, 2015). Receamos, nesse exemplo, a redução da interpretação dos elementos próprios do convívio e da cultura de distintos grupos a objetos específicos.

(EF09CI15) Habilidade proposta ao $9^{\circ}$ ano de Ciências - objeto de conhecimento referente à "astronomia e cultura".

"Relacionar diferentes leituras do céu e explicações sobre a origem da Terra, do Sol ou do Sistema Solar às necessidades de distintas culturas (agricultura, caça, mito, orientação espacial e temporal etc.)" (BRASIL, 2018, p. 351).

De maneira semelhante ao caso anterior, se trabalhada de forma isolada, essa habilidade também pode se reduzir a abordagens multiculturais folcloristas e fragmentadas (CANEN, 2015). No entanto, dados os vários aspectos que são ressaltados em relação a distintos modos de vida e cultura, que tratam desde a agricultura à orientação espacial e temporal, acreditamos que essa habilidade tem um potencial interessante para fomentar aprendizagens multiculturais críticas. Ressaltamos, também, o necessário cuidado de não se discutirem as distintas explicações do mundo e de modos de vida de forma simplista, o que pode levar tais vertentes de conhecimento a serem vistas como menores, frente às explicações e estratégias utilizadas pela Ciência (BARBOSA, 2010).

As próximas duas habilidades tratam de perspectivas e problemáticas parecidas: 
(EF07CI06) Habilidade proposta ao $7^{\circ}$ ano de Ciências - objeto de conhecimento referente à "história dos combustíveis e das máquinas térmicas".

"Discutir e avaliar mudanças econômicas, culturais e sociais, tanto na vida cotidiana quanto no mundo do trabalho, decorrentes do desenvolvimento de novos materiais e tecnologias (como automação e informação)" (BRASIL, 2018, p. 347).

(EF09CI12) Habilidade proposta ao $9^{\circ}$ ano de Ciências - objeto de conhecimento referente à "preservação da biodiversidade".

"Justificar a importância das unidades de conservação para a preservação da biodiversidade e do patrimônio nacional, considerando os diferentes tipos de unidades (parques, reservas e florestas nacionais), as populações humanas e atividades a eles relacionados” (BRASIL, 2018, p. 349).

Nessas duas situações, as habilidades propostas expõem de modo abrangente a relevância de assuntos referentes à pluralidade de usos de materiais e de modos de vida. Nesse caso, um cuidado que se precisa ter na concretização curricular é que esses temas não sejam apenas acessórios, mas que assumam papel central nas ações em sala de aula.

(EF08CI11) Habilidade proposta ao $8^{\circ}$ ano de Ciências - objeto de conhecimento referente à "sexualidade".

"Selecionar argumentos que evidenciem as múltiplas dimensões da sexualidade humana (biológica, sociocultural, afetiva e ética)" (BRASIL, 2018, p. 347).

Para essa habilidade, embora se reconheça que a sexualidade humana se constrói com uma multiplicidade de aspectos, a redação do texto se apresenta vaga, pois "selecionar argumentos", sem mais discussões ou problematizações, pode conduzir apenas ao reconhecimento da existência da diferença (BARBOSA, 2010), não abrangendo as aprendizagens no âmbito dos valores, o que incluiria menções ao respeito e ao engajamento público.

Não pudemos deixar de notar a ausência de temas polêmicos nessa versão da BNCC, se comparada à anterior. No que diz respeito à habilidade que acabamos de apresentar, constatamos que, na versão de 2017, havia a inserção do respeito, do acolhimento e da valorização da diversidade, como se pode observar no trecho a seguir: 
Selecionar argumentos que evidenciem as múltiplas dimensões da sexualidade humana (biológica, sociocultural, afetiva e ética) e a necessidade de respeitar, valorizar $e$ acolher a diversidade de indivíduos, sem preconceitos baseados nas diferenças de gênero (BRASIL, 2017, p. 301, grifos nossos).

Julgamos que a exclusão ativa e intencional da discussão de gênero denota a banalização de um tema de grande valor social, o que pode levar à promoção da naturalização de desigualdades e de preconceitos enraizados no corpo de uma sociedade reconhecidamente machista, que ingenuamente ainda vê temáticas ligadas às diferenças de gênero como uma pauta desnecessária ou como tabu, porque ataca costumes tradicionais (SILVA, 1999; BARBOSA, 2010). Dessa forma, ao analisarmos de modo geral o multiculturalismo presente na versão final da BNCC, para a área de Ciências da Natureza, concluímos que o texto acaba por minimizar aspectos próprios ao multicultural, ao diverso e ao diferente.

Comparando os resultados obtidos na análise das habilidades em Ciências com as intenções declaradas como justificativas no texto geral da base, podemos notar a presença de um viés reparador na BNCC. Para essa concepção, a preocupação com o plural se resume a estratégias de acesso (CANEN, 2015). Barbosa (2010) evidencia uma perspectiva semelhante, porém a chama de "assimilacionista". Propostas desse tipo entendem que a sociedade é plural e que não existem oportunidades iguais a todos. Por isso, contentam-se em buscar apenas a integração dos excluídos à cultura hegemônica, sem alterar as mentalidades predominantes que geram tal disparidade.

Tal perspectiva, de certo modo, pode ser comparada a críticas anteriores à finalização da Base, representadas nesse texto por autores como Triches e Aranda (2016), Cunha e Silva (2016) e Sousa (2015), que defendiam que a Base poderia apresentar um viés homogeneizador, em relação às experiências de vida e de saberes, que levariam a uma perda ou à exclusão de temáticas ligadas às diferenças, à diversidade, às identidades e às culturas. Como efeito, nota-se uma evidente diminuição de discussões associadas às temáticas multiculturais na versão final da BNCC.

Defendemos, como pressuposto de um regime democrático, políticas que viabilizem acesso a espaços distintos, principalmente o educativo, que é indiscutivelmente desigual. Todavia, o tratamento à pluralidade não deve se resumir só a isso, uma seleção cultural relevante deve contemplar também a valorização e o engajamento pelo direito à diferença (SANTOMÉ, 2012). 
Por fim, acreditamos que, como educadores ou educadoras, devemos superar tentativas de ocultarem-se questões ligadas à diversidade e ao multiculturalismo e evidenciar que a BNCC, como se apresenta para a aprendizagem em Ciências, demonstra um esvaziamento de questões plurais. Torna-se necessário, portanto, rever qual o valor que deve ser dado ao multiculturalismo frente ao objetivo do letramento científico, de modo que ele passe a ser reconhecido como integrante da formação e não somente um tema acessório.

\section{CONSIDERAÇÕES FINAIS}

Gostaríamos de retomar a importância da BNCC para o contexto escolar, como um documento que fundamenta uma série de aprendizagens essenciais à formação básica. As aprendizagens essenciais apresentadas não caracterizam em si práticas pedagógicas, mas possuem potencial para influenciá-las, na medida em que legitimam e orientam a confecção de materiais didáticos e de propostas pedagógicas municipais e estaduais. Assim, devemos reconhecer a influência que esse documento terá sobre a vida de diversos estudantes.

Dada a capacidade da BNCC de orientar a aprendizagem nacional, salientamos a seriedade dos dados que obtivemos para a área de Ciências da Natureza no Ensino Fundamental. Da análise das habilidades para a área das Ciências da Natureza, em relação ao multiculturalismo, notamos uma evidente discordância com aquilo que é apresentado nos textos introdutórios do documento e da área de Ciências. Esse resultado foi a maior contribuição trazida pelo nosso trabalho.

Correlacionada à explicitação da incoerência entre argumentos utilizados para justificar ou defender a BNCC e o produto formulado para a área de Ciências da Natureza, nossos dados demonstraram uma situação preocupante: as aprendizagens essenciais adotadas como caminho para a intervenção e a participação social estão distantes de um tratamento adequado à pluralidade. Dessa maneira, o que vimos na BNCC de Ciências é um silenciar de culturas, de identidades, de modos de vida; enfim, uma quase negação àquilo que é diferente, quando sabemos que ser alheio a tal fato é ser conivente com desigualdades, discriminações e relações de poder (CANEN, 2007).

Por outro lado, não devemos ceder ao pessimismo desses dados; pelo contrário, como afirma Santomé (2012), precisamos unir nossos esforços políticos e pedagógicos em busca de 
uma educação consistente, reflexiva e que possibilite de fato uma formação feita por humanos e para humanos. Defendemos que o ensino deve ser crítico e não alheio à realidade em que convivemos, a qual deve ser transformada, desconstruída, construída e reconstruída. Tal atitude pede uma atenção aos conteúdos culturais que escolhemos, como um corpo social, para as futuras gerações.

Por fim, é de suma importância destacarmos que esse trabalho não é o primeiro pautado na investigação da BNCC e não deve ser o último. Seria interessante que novos estudos fossem realizados para as outras áreas, a fim de avaliarmos se a tendência, aqui observada, também se verifica nos demais componentes curriculares.

\section{REFERÊNCIAS}

BARBOSA, Ana Carolina Ayres Pereira. Ensino de Ciências e pluralidade cultural: professores de ciências e temáticas multiculturais no currículo. 2010. Orientador: Marcelo Gustavo Andrade de Souza. Dissertação (Mestrado em Educação) - Departamento de Educação do Centro de Teologia e Ciências Humanas, Pontifícia Universidade Católica do Rio de Janeiro, Rio de Janeiro, 2010.

BARDIN, Laurence. Análise de conteúdo. 6. ed. Lisboa, Portugal: Edições 70, 2006.

BATISTA, Antônio Augusto Gomes; RIBEIRO, Vanda Mendes. Consensos e dissensos em torno de uma Base Nacional Comum Curricular no Brasil, relatório de pesquisa. CENPEC: Centro de Estudos e Pesquisas em Educação, cultura e Ação Comunitária. São Paulo, fev. 2015. Disponível em:

http://ftp.cenpec.org.br/com/portalcenpec/biblioteca/Consensos_e_Dissensos_Relatorio_Pesq uisa_Cenpec_Final.pdf. Acesso em: 24 out. 2017.

BRASIL. Base Nacional Comum Curricular. Brasília: Ministério da Educação, 2017. Disponível em: http://basenacionalcomum.mec.gov.br/images/BNCC_publicacao.pdf. Acesso em: 16 abr. 2017.

BRASIL. Base Nacional Comum Curricular. Brasília: Ministério da Educação, 2018. Disponível em: http://basenacionalcomum.mec.gov.br/a-base. Acesso em: 9 set. 2019.

BRASIL. Lei No 9.394, de 20 de dezembro de 1996. Estabelece as diretrizes e bases da educação nacional. Brasília: Presidência da República, Casa Civil, Subchefia para Assuntos Jurídicos, [1996]. Disponível em: http://www.planalto.gov.br/ccivil_03/leis/19394.htm. Acesso em: 10 set. 2019.

BRASIL. Ministério da Educação. Secretaria de Educação Básica. Secretaria de Educação Continuada, Alfabetização, Diversidade e Inclusão. Secretaria de Educação Profissional e Tecnológica. Conselho Nacional de Educação. Câmara de Educação Básica. Diretrizes 
Curriculares Nacionais da Educação Básica. Brasília: MEC; SEB; DICEI, 2013.

Disponível em:

http://portal.mec.gov.br/index.php?option=com_docman\&view=download\&alias $=13448$ diretrizes-curiculares-nacionais-2013-pdf\&Itemid=30192. Acesso em: 5 maio 2018.

CACHAPUZ, António et al. A necessária renovação do ensino das ciências. São Paulo: Cortez, 2005.

CACHAPUZ, António; PRAIA, João; JORGE, Manuela. Da educação em ciência às orientações para o ensino das ciências: um repensar epistemológico. Ciência e Educação, Bauru, v. 10, n. 3, p. 363-381, 2004.

CANEN, Ana. Educação multicultural, identidade nacional e pluralidade cultural: tensões e implicações curriculares. Cadernos de Pesquisa, São Paulo, n. 111, p. 135-149, dez. 2000.

CANEN, Ana. O Multiculturalismo e seus dilemas: implicações na educação. Comunicação e Política, Rio de Janeiro, v. 25, n. 2, p. 91-107, jan. 2007.

CANEN, Ana. Sentidos e dilemas do multiculturalismo: desafios curriculares para o novo milênio. In: LOPES, Alice Casimiro; MACEDO, Elizabeth (Orgs.). Currículo: debates contemporâneos. 3. ed. São Paulo: Cortez, 2015. p. 174-195.

CARVALHO, Janete Magalhães; SILVA, Sandra Kretli; DELBONI, Tânia Mara Zanotti Guerra Frizzera. A Base Nacional Comum Curricular e a produção biopolítica da educação como formação de "capital humano". Revista e-Curriculum, São Paulo, v. 15, n. 2, p. 481503, abr./ jun. 2017.

CUNHA, Kátia Silva; SILVA, Janini Paula. Sobre bases e bases curriculares, nacionais, comuns: de que currículo estamos falando? Revista e-Curriculum, São Paulo, v. 14, n. 4, p. 1236-1257, out. /dez. 2016.

FERREIRA, Fernanda Nunes. Multiculturalismo e currículo escolar: desafios e possibilidades no Ensino Fundamental. 2012. Orientadora: Maria Angélica Rodrigues Martins. Dissertação (Mestrado em Educação) - Universidade Católica de Santos, Santos, 2012.

FRANCO, Maria Laura Puglisi Barbosa. Análise de conteúdo. 2. ed. Brasília: Liber Livro Editora, 2005.

GOMES, Nilma Lino. Indagações sobre o currículo: Diversidade e currículo. Brasília: Ministério da Educação, Secretaria da Educação Básica, 2007. Disponível em: http://portal.mec.gov.br/seb/arquivos/pdf/Ensfund/indag4.pdf. Acesso em: 6 jun. 2017.

JAFELICE, Luiz Carlos. A formação docente (em ciências naturais): para quê? Para quem? In: NORONHA, Claudianny Amorim; SÁ JÚNIOR, Lucrécio Araújo de (Orgs.). Por uma formação para a docência. Natal: EDURFN, 2017. p. 145-175. Disponível em: 
repositorio.ufrn.br/jspui/bitstream/123456789/23540/7/Por\%20uma\%20formação\%20para\%2 0a\%20docência.pdf. Acesso em: 1 jan. 2020.

KRASILCHICK, Myriam. Perspectivas do ensino de biologia. In: KRASILCHICK, Myriam (Org.). Prática do Ensino de Biologia. 4. ed. São Paulo: Editora da Universidade de São Paulo (Edusp), 2016. p. 185-196.

LEWONTIN, Richard. Um ceticismo racional. In: LEWONTIN, Richard (Org.). Biologia como ideologia- a doutrina do DNA. São Paulo: FUNPEC, 2001. p. 7-21.

LIBÂNEO, José Carlos. As relações "dentro-fora" na escola ou as interfaces entre práticas socioculturais e ensino. In: LIBÂNEO, José Carlos; ALVES, Nilda (Orgs.). Temas da Pedagogia: diálogos entre didática e currículo. São Paulo: Cortez, 2012. p. 333-349.

MERCADO, Elisangela Leal de Oliveira; FUMES, Neiza de Lourdes Frederico. Base Nacional Comum Curricular e a educação especial no contexto da inclusão escolar. In: ENCONTRO INTERNACIONAL DE FORMAÇÃO DE PROFESSORES E FÓRUM PERMANENTE DE INOVAÇÃO EDUCACIONAL, 10., 2017, Aracaju. Anais eletrônicos [...]. Aracaju: Universidade Tiradentes. Disponível em: https://eventos.set.edu.br/index.php/enfope/article/view/4770. Acesso em: 22 out. 2017.

MOREIRA, Antonio Flavio Barbosa; CANDAU, Vera Maria. Indagações sobre o currículo: currículo, conhecimento e cultura. Brasília: Ministério da Educação, Secretaria da Educação Básica, 2007. Disponível em: http://portal.mec.gov.br/seb/arquivos/pdf/Ensfund/indag3.pdf. Acesso em: 10 jun. 2017.

MOREIRA, Carmen Tereza Velanga. As contribuições do pensamento do canadense Peter McLaren e de Paulo Freire para a construção de uma educação multicultural inclusiva. In: NENEVÉ, Miguel; PROENÇA, Marilene (Orgs.). Educação e diversidade: interfaces Brasil - Canadá. São Paulo: Casa do Psicólogo, 2005. p. 87-108.

MORIN, Edgar. Para a ciência. In: MORIN, Edgar. Ciência com consciência. Rio de Janeiro: Editora Bertrand Brasil LTDA, 2008. p.15-36.

SANTOMÉ, Jurjo Torres. Currículo escolar e justiça social: o cavalo de troia da educação. Porto Alegre: Penso, 2013.

SANTOMÉ, Jurjo Torres. Os conteúdos culturais, a diversidade cultural e a função das instituições escolares. In: SANTOMÉ, Jurjo Torres. Globalização e interdisciplinaridade: o currículo integrado. Porto Alegre: Artes Médicas, 1998. p. 129-152.

SANTOS, Jose Luiz dos. O que é cultura. 16. ed. São Paulo: Brasiliense, 2017.

SANTOS, Lucíola Licínio de C. P.; LOPES, José de Souza Miguel. Globalização, multiculturalismo e currículo. In: MOREIRA, Antonio Flávio Barbosa (Org.). Currículo: questões atuais. 14. ed. Campinas: Papirus Editora, 2008. p. 29-39. 
SILVA, Tomaz Tadeu da. Documentos de identidade, uma introdução às teorias do currículo. 2. ed. Belo Horizonte: Autêntica, 1999.

SODRÉ, Muniz; TRINDADE, Azoilda Loretto. Cultura, diversidade cultural e educação. In: TRINDADE, Azoilda Loretto da; SANTOS, Rafael dos (Orgs.). Multiculturalismo: mil e uma faces da escola. 3. ed. Rio de Janeiro: DP\&A, 2002. p. 17-32.

SOUSA, Jorge Luis Umbelino de. Currículo e projetos de formação: Base Nacional Comum Curricular e seus desejos de performance. Espaço do Currículo, João Pessoa, v. 8, n. 3, p. 323-334, set./out. 2015.

TRICHES, Eliane de Fátima; ARANDA, Maria Alice de Miranda. A formulação da Base Nacional Comum Curricular (BNCC) como ação da política educacional: breve levantamento bibliográfico (2014-2016). Realização: Revista Online de Extensão e Cultura, Dourados, v. 3, n. 5, p. 81-96, 2016.

Enviado em: 01/07/2018

Aprovado em: 19/09/2019 